\title{
Acute Leriche Syndrome due to Embolisation of an Atrial Myxoma
}

Peeters $\mathbf{K}^{1^{*}}$, Avet $\mathrm{J}^{1}$, Daenen $\mathbf{G}^{1}$, Stabel $\mathbf{P}^{1}$, Bronckaers $\mathbf{M}^{2}$, Rega $\mathrm{F}^{3}$, Bekaert $\mathrm{I}^{4}$ and Van Reet $\mathrm{B}^{4}$

${ }^{1}$ Department of Vascular Surgery, AZ Turnhout, B-2300 Turnhout, Belgium

${ }^{2}$ Department of General and Abdominal Surgery, AZ Turnhout, B-2300 Turnhout, Belgium

${ }^{3}$ Department of Vascular Surgery, KU Leuven - University of Leuven, University Hospitals Leuven, B-3000 Leuven, Belgium

${ }^{4}$ Department of Cardiology, AZ Turnhout, B-2300 Turnhout, Belgium

*Corresponding author: Karen Peeters, Department of Vascular Surgery, AZ Turnhout, B-2300 Turnhout, Belgium,Tel: 3214404069 ; Fax: 32 14 406871 ; E-mail: karen.peeters1@student.kuleuven.be

Rec date: Jul 07, 2015; Acc date: Jul 31, 2015; Pub date: Aug 02, 2015

Copyright: (C) 2015 Peeters K, et al. This is an open-access article distributed under the terms of the Creative Commons Attribution License, which permits unrestricted use, distribution, and reproduction in any medium, provided the original author and source are credited.

\begin{abstract}
The presentations of cardiac myxoma are diverse, from asymptomatic to a variety of symptoms due to

embolisation. Total occlusion of the abdominal aorta due to embolisation of an atrial myxoma is a rare but lifethreatening event which demands an urgent diagnosis and prompt intervention with embolectomy.

In this paper a patient with acute onset paraplegia is presented. CT angiography revealed a large totally occlusive thrombus in the infrarenal abdominal aorta extending into the common iliac arteries. A thrombus in the left atrium was identified as the source of the embolus.
\end{abstract}

Keywords: Atrial myxoma; Acute occlusion of abdominal aorta; Acute Leriche syndrome; TakotsuboCardiomyopathy

\section{Case Report}

A 68-year-old patient was admitted to the emergency department after a fall during a bike ride because of sudden dizziness. Initially she only had a feeling of discomfort and weakness in the lower extremities en was still able to stand. Shortly afterwards this progressed to paralysis in both legs. Her medical history included diabetes mellitus and active smoking. On admission, the patient was in poor clinical condition with mild tachycardia and fluctuations in blood pressure. She was confused, anxious and sweaty but obeying commands. Clinical examination showed pallor, coldness and paralysis of both legs. Femoral, popliteal and pedal pulses were absent.

CT angiography revealed a large totally occlusive thrombus in the infrarenal abdominal aorta extending into the common iliac arteries. A thrombus in the left atrium was identified as the source of the embolus (Figures 1 and 2). Electrocardiography showed ST-segment elevation, consistent with an acute lateral myocardial infarction, and the patient had significantly elevated Troponin I levels.

\section{Procedure}

Intravenous heparin infusion was started and the patient was transferred to the operation theatre for a bilateral transfemoral embolectomy.

Longitudinal groin incisions were made to expose the common femoral arteries and their bifurcation. A size 5 Fogarty was then passed up to the aorta bilaterally with retrieval of a transparent, gelatinous embolus. Biopsies were taken. There was no retrieval of any thrombus distally but there was adequate backflow. Closure of the femoral arteries was done with patch angioplasty after endarterectomy because of severe occlusive pathology.

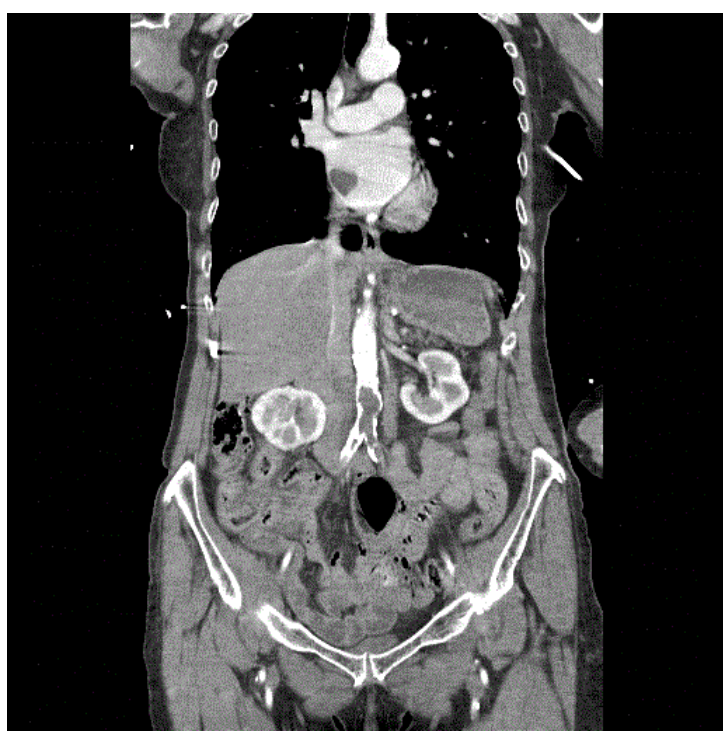

Figure 1: CT angiography showing a large totally occlusive thrombus in the abdominal aorta and a mass in the left atrium as the source of embolus.

Fasciotomy was not considered because there were no signs of compartment syndrome in the lower extremities. At the end of the procedure both lower extremities were warm and had good capillary refill. 
The patient required inotropic support and was transferred - intubated - to the ICU.

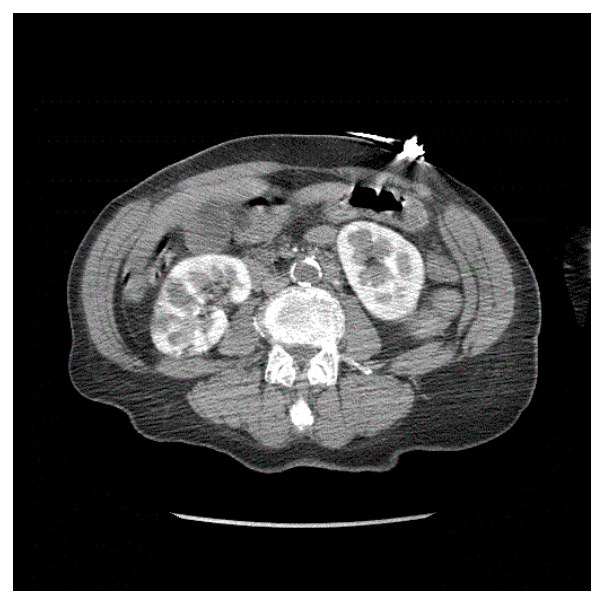

Figure 2: CT angiography showing a large totally occlusive thrombus in the infrarenal aorta.

\section{Post-operative}

Trans-esophageal echocardiography showed a friable mass with irregular margin and central necrosis in the left atrium $(2.3 \mathrm{~cm} \times 2.2$ $\mathrm{cm}$ ) (Figure 3). There was apical ballooning with a large zone of apical, anteroseptal and anterolateral akinesis and contraction of the basal segments only. Left ventricle ejection fraction was reduced to $26 \%$. Coronary angiography showed no significant coronary heart disease and the patient was diagnosed with Takotsubo cardiomyopathy [1].

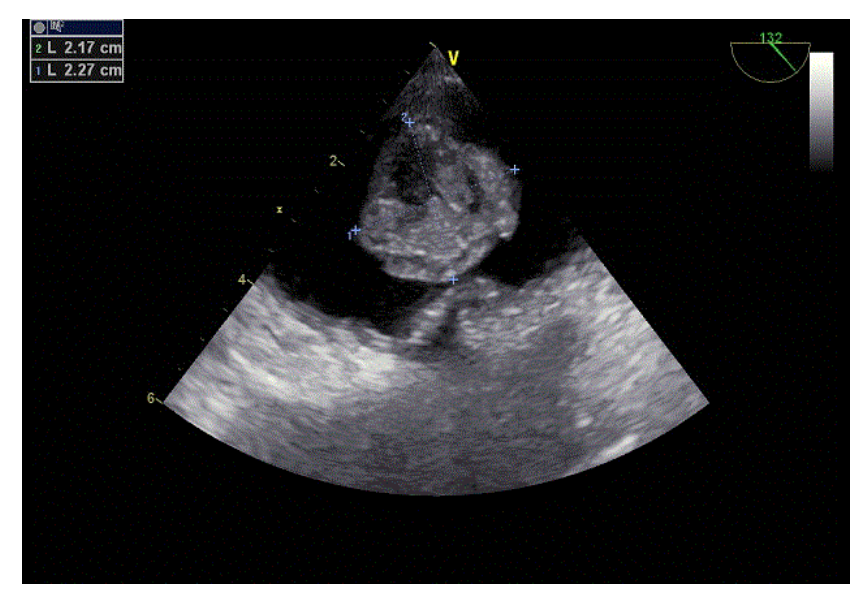

Figure 3: Trans-esophageal echocardiography showed a friable mass with irregular margin and central necrosis in the left atrium $(2.3 \mathrm{~cm} \times 2.2 \mathrm{~cm})$.

Histological analysis of the specimen demonstrated short cords of globular myxoma cells embedded in a myxoid stroma. These findings were consistent with the diagnosis of embolisation of an atrial myxoma.

The patient was transferred to a university hospital for resection of the myxoma.
The resection was performed through median sternotomy with the aid of cardiopulmonary bypass and using a right atriotomy and transseptal approach. The myxoma was identified, attached laterally near the pulmonary vein, and resected in toto. Complete resection was confirmed visually and by ultrasound.

After the operation the patient was admitted to the intensive care unit for weaning and vasopressor support. After extubation this support could easily be stopped and there were no clinical signs of cardiac decompensation.

Transthoracic echocardiography showed no dilatation of the atria and a good in- and outflow of both ventricles.

On day three, the patient was transferred to the regular hospital ward where the postoperative course was complicated by a pneumothorax for which a chest tube was placed. The patient also developed urosepsis which was treated with IV antibiotics.

On day fifteen she was able to leave the hospital in good clinical condition. Follow-up transthoracic echocardiograph after one month showed normal dimensions of both atria and a good systolic function of both ventricles.

\section{Discussion}

Myxoma is the most common primary cardiac tumour with $90 \%$ of the cases occurring in the atria, mainly the left atrium. Myxomas are neoplasms of endocardial origin. The malignant potential remains doubtful, but there are a few reports of the remote growth of myxomatous material that has embolized [2].

A study by Pinede et al. of 112 cases of atrial myxoma from 1959-1998 showed that systemic embolisation is a common presentation apart from cardiac obstruction and systemic symptoms [3]. More than two thirds of myxomatous emboli migrate to the central nervous system, but any arterial bed may be affected. Recorded cases document emboli in the upper and lower extremities, aortic saddle, coronary arteries, kidneys, liver, spleen, eye, skin, and more [2]. Although the higher prevalence of atrial myxoma in female, systemic embolisation occurs more frequent in male.

The treatment of choice for myxomas is surgical removal. After the diagnosis has been established, surgery should be performed promptly, because of the possibility of embolic complications or sudden death.

Acute occlusion of the abdominal aorta due to embolisation of an atrial myxoma is rare but several cases have been reported [4-7].

The clinical presentation is mostly sudden and characterized by pain in the lower extremities, palor, paraesthesia and paralysis. Depending on the degree of occlusion, distal pulses will be weak or absent.

However, the clinical presentation can be misleading as neurologic symptoms of the lower extremities can predominate and the diagnosis can be mistaken for stroke or a central nervous system lesion.

Management of this condition involves intravenous heparin infusion followed by an emergency embolectomy. Aortoiliac embolectomy via bilateral common femoral arteriotomies is the preferred procedure. If adequate inflow cannot be reestablished, an extra-anatomic bypass is performed [8].

Prompt recognition of the condition, supportive care and early surgical referral are the cornerstones of management of acute aortic occlusion. A delay in diagnosis prolongs time to appropriate intervention and comes with increased mortality and morbidity. 
Citation: Peeters K, Avet J, Daenen G, Stabel P, Bronckaers M, et al. (2015) Acute Leriche Syndrome due to Embolisation of an Atrial Myxoma. J Vasc Med Surg 3: 214. doi:10.4172/2329-6925.1000214

Page 3 of 3

Ischemic complications including gastrointestinal malperfusion, renal infarction, and paralysis secondary tot spinal cord ischemia can occur. Rhabdomyolysis is a frequent complication, and the use of additional contrast associated with catheter-based techniques of revascularization may place the patient at increased risk of further renal insufficiency [9].

In conclusion, the diagnosis of embolisation of a myxoma should be strongly suspected in acute onset of paraplegia, especially in younger patients. Surgery should be performed urgently to retrieve the emboli and to decrease the risk of ischemia and reperfusion injury.

\section{References}

1. Scantlebury DC, Prasad A (2014) Diagnosis of Takotsubo cardiomyopathy. Circ J 78: 2129-2139.

2. Reynen K (1995) Cardiac Myxomas. N Engl J Med 333: 1610-1617.

3. Pinede L, Duhaut P, Loire R (2001) Clinical presentation of left atrial cardiac myxoma. A series of 112 consecutive cases. See comment in PubMed Commons below Medicine (Baltimore) 80: 159-172.
4. Neff CM, McCowan CL (2008) Complete aortic occlusion caused by cardiac myxoma emboli. See comment in PubMed Commons below Am J Emerg Med 26: 110.

5. Huang C-Y, Chang Y-Y, Hsieh M-Y, Hsu C-P (2012) Atrial myxoma presenting as total occlusion of the abdominal aorta and its major four branches. J Chin Med Assoc 75: 349-352.

6. Yadav S, Alvarez JM (2009) Catastrophic presentation of atrial myxoma with total occlusion of abdominal aorta. Interact Cardiovasc Thorac Surg 9: 913-915.

7. Lin YH, Chen SY, Liu KL, Wu IH, Huang SC, et al. (2010) Queer consequence of cough: atrial myxoma embolization with acute occlusion of the abdominal aorta. Am J Emerg Med 28: 261.e1-2.

8. Lorenz EP, Trabhardt S, Diermann J, Weber B, Boese-Landgraf J (1995) Current treatment strategies in acute distal aortic occlusion. Zentralbl Chir. 120: 195-201.

9. Crawford JD, Perrone KH, Wong VW, Mitchell EL, Azarbal AF, et al. (2014) A modern series of acute aortic occlusion. J Vasc Surg. Society for Vascular Surgery 59: 1044-1050. 